\title{
ABA/ASB structural biology session II 2018
}

\author{
Marc Kvansakul ${ }^{1}$ (D)
}

Received: 9 April 2019 / Accepted: 15 April 2019 / Published online: 26 April 2019

(C) International Union for Pure and Applied Biophysics (IUPAB) and Springer-Verlag GmbH Germany, part of Springer Nature 2019

The afternoon structural biology session 2 on Monday, December 3, featured an exciting selection of contemporary protein structure-focused presentation. The session was opened by Associate Professor Michelle Dunstone from the Department of Biochemistry \& Molecular Biology at Monash University, who discussed the mechanism of action of the $\mathrm{MACPF} / \mathrm{CDC}$ family of pore-forming proteins. In particular, Associate Professor Dunstone was focusing her latest structure of the C9 protein, a component of the complement cascade which forms a critical arm of innate immunity (Spicer et al. 2018). The C9 structure was determined to near-atomic resolution using cryo-electron microscopy in a fully assembled state within a lipid bilayer. Excitingly, her structure suggested a novel mechanism for the assembly of MACPF/CDC protein oligomeric complexes.

The next speaker was Professor Quan Hao from City University of Hong Kong, who shared his recent advances on understanding the enigmatic family of sirtuin proteins. Sirtuins act as erasers or readers of posttranslational modifications by removing modifications such as acyl groups from lysine residues on substrates, thus allowing sirtuins to modulate autoimmune and inflammatory processes with high efficiency. A highlight was the description of the capture of an intermediate deacetylation state for SIRT2, thus providing the first atomic resolution evidence for a two-step catalysis model (Wang et al. 2017).

The next three speakers were part of an exciting group of early career scientists from Asia and Australia in structural biology. Dr. Midori Murakami from the Department of

This article is part of a Special Issue dedicated to the '2018 Joint Conference of the Asian Biophysics Association and Australian Society for Biophysics' edited by Kuniaki Nagayama, Raymond Norton, Kyeong Kyu Kim, Hiroyuki Noji, Till Böcking, and Andrew Battle.

Marc Kvansakul

m.kvansakul@latrobe.edu.au

1 La Trobe Institute for Molecular Science, La Trobe University, Melbourne, Australia
Physics at Nagoya University presented her work on an unusual rhodopsin protein from squid. She was able to determine rhodopsin structures in different photoactivated states, thus illuminating the structural transitions during photon absorption. Transition through the different states was achieved by varying temperatures from 100 to $170 \mathrm{~K}$ during rhodopsin illumination, thus allowing the capture of different stable retinal configurations (Murakami and Kouyama 2015).

This was followed by Dr. Josep Font from the School of Medical Sciences at the University of Sydney, who presented data combining electrophysiology and X-ray crystallography to understand the transit of chloride ions across excitatory amino acid transporters such as the glutamate transporters. In particular, he focused on the chloride ion permeation pathway in the archaeal amino acid transporter GltPh.

The final speaker in the session was Sophie Hertel from the EMBL node for Single Molecule Sciences at the University of New South Wales, who presented her recent attempts to assembly the flagellar motor protein Flig on immobilized designer DNA sequences in order to measure the kinetics of Flig protein interactions during motor assembly.

\section{References}

Spicer BA, Law RHP, Caradoc-Davies TT, Ekkel SM, Bayly-Jones C, Pang SS, Conroy PJ, Ramm G, Radjainia M, Venugopa $1 \mathrm{H}$, Whisstock JC, Dunstone MA (2018) The first transmembrane region of complement component-9 acts as a brake on its self-assembly. Nat Commun 9:3266

Wang Y, Fung YME, Zhang W, He B, Chung MWH, Jin J, Hu J, Lin H, Hao Q (2017) Deacylation mechanism by SIRT2 revealed in the 1'SH-2'-O-myristoyl intermediate structure. Cell Chem Biol 24:339345

Murakami M, Kouyama T (2015) Crystallographic study of the LUMI intermediate of squid rhodopsin. PLoS One 10:e0126970

Publisher's note Springer Nature remains neutral with regard to jurisdictional claims in published maps and institutional affiliations. 